\title{
Sonographic assessment of the portal vein diameter in apparently healthy adults in a Northern Nigerian population.
}

\author{
Geofery Luntsi ${ }^{1}$, Mohammed Sani ${ }^{1}$, Joseph Dlama Zira ${ }^{2}$, Nwobi Chigozie Ivor ${ }^{1}$, Sani H Garba ${ }^{3}$
}

1. Department of Medical Radiography, College of Medical Sciences, University of Maiduguri, Borno State, Nigeria 2. Department of Radiology Abubakar Tafawa Balewa University Teaching Hospital Bauchi, Bauchi State, Nigeria.

3. Department of Human Anatomy, College of Medical Sciences, University of Maiduguri, Borno State, Nigeria

\begin{abstract}
Background: Sonography is a valuable tool in the assessment of porto-systemic pathologies. This study aimed at determining the mean portal vein diameter based on age, gender and anthropometric variables.

Methods: A cross sectional study conducted among 201 apparently healthy adults in Bauchi Metropolis. Participants were recruited from the school of nursing AbubakarTafawa Balewa Teaching Hospital (ATBUTH), Bauchi. Ultrasound machine ALOKA SSD-1000, (IP-1233EV, SN-57324, Japan) with curvilinear transducer with frequency of 3-5MHz was used for a period of four months, (December 2015 to April 2016). Participants' heights were measured while standing against a meter rule with the head in Frankfurts' position and weight measured using a weighing scale. Data analysis was done using SPSS version 22.0. Descriptive statistics (mean, standard deviation), and Pearson's Correlation were used.

Results: The mean portal vein diameter was $9.60 \pm 1.41 \mathrm{~mm}$ for both sexes. The mean value for males was $9.71 \pm 1.42 \mathrm{~mm}$, and $9.35 \pm 1.46 \mathrm{~mm}$ among females. There was a positive correlation correlation between the PV diameter and Body Mass Index (P $\leq 0.01)$.
\end{abstract}

Conclusion: This study found the mean values of PV diameter in apparently healthy adults in our environment to be $9.60 \pm$ $1.41 \mathrm{~mm}$ and that PV diameter positively correlates with anthropometric variables.

Keywords: Portal vein diameter, sonography, Nigerian population, healthy adults.

DOI: http://dx.doi.org/10.4314/ahs.v16i4.35

Cite as: Luntsi G, Sani M, Zira JD, Ivor NC, Garba SH. Sonographic assessment of the portal vein diameter in apparently healthy adults in a northern Nigerian population. Afri Health Sci. 2016;16(4): 1163-1168. http:// dx.doi.org/10.4314/ahs.v16i4.35

\section{Introduction}

The portal vein (PV) and hepatic artery forms the liver's dual blood supply. Majority (about 75\%) of hepatic blood flow is derived from portal vein while the remainder comes from the hepatic artery. The portal vein (PV) is formed by the confluence of superior mesenteric vein and splenic vein, behind the neck of the pancreas at the level of second lumbar vertebra ${ }^{1}$. Sonographic measurement of the portal vein diameter is a corner stone and also has a reasonable accuracy in diagnosing patients suspected of having portal hypertension ${ }^{2}$. The intricate rela-

\section{Corresponding author:}

Geofery Luntsi.

Department of Medical Radiography,

College of Medical Sciences,

University of Maiduguri, Borno State, Nigeria

Email: geostuffy@unimaid.edu.ng, geostuffy@yahoo.com tionship between the liver and the portal vein maintains homeostasis in the human body ${ }^{1}$.

The major abnormality of the portal venous system is portal hypertension which may occur due to increased resistance to portal blood flow due to alterations in the liver architecture that leads to enlargement of extrahepatic and intrahepatic portal vessels and the development of portosystemic collaterals ${ }^{3}$.The formation of portosystemiccollaterals may leads to splenomegaly, ascites, encephalopathy among others ${ }^{4}$. Diagnostic imaging methods like portal venography, splenoportography, and arteriography have been used to evaluate patients suspected of having portal thrombosis which are invasive, expensive, time consuming and involve risk and discomfort to the patient, while computed tomography and magnetic resonance imaging have advantages of better cross sectional images but are both expensive and the former exposes patient to high doses of ionizing radiation ${ }^{5,7}$.

African Health Sciences Vol 16 Issue 4, December, 2016 
Sonography, in addition to its use of non-ionizing radiation, its accessibility, non-invasive nature, portability, low cost and ability of rapid accomplishment, makes it a good diagnostic tool which plays a great role in the diagnosis and follow up of patients with portal hypertension ${ }^{2}$. These examinations are often challenging and sonographers must be confident in their use and manipulation of equipment, and have thorough knowledge and understanding of the anatomy and pathophysiology of the disease process.

This study therefore intends to determine the mean values of portal vein diameter in apparently healthy Northern Nigerian adults.

\section{Materials and methods}

This was a cross-sectional prospective study carried out among apparently healthy adult subjects in Abubakar Tafawa Balewa University Teaching Hospital (ATBUTH) Bauchi, for a period of four months from December, 2015 to April, 2016. Ethical clearance was obtained from the ethical committee and the head of Radiology department in Abubakar Tafawa Balewa University Teaching Hospital, Bauchi, and informed consent was obtained from all the participants, prior to the study. Participants were recruited (Voluntarily) from the school of Nursing ATBUTH, Bauchi and other staff of the hospital who gave their consent.

Inclusion and exclusion criteria: Apparently healthy individuals with normal ultrasound findings of the liver formed the inclusion criteria while ill individuals, pregnant women, subjects on hepatotoxic drugs such as anti-tuberculous and antiretroviral drugs were excluded from the study.

\section{Equipment used}

An ultrasound machine ALOKA SSD-1000, (IP-1233EV, SN-57324, Japan) with curvilinear transducer with a frequency of $3.5 \mathrm{MHz}$ was used. Quality control maintenance check was routinely performed on the equipment by the medical physicist of the department prior to measurements. Measurements were carried out using the electronic calipers of the ultrasound machine after freezing the image.

Anthropometric parameters, like height, weight and body mass index of each participants were measured, Participants' heights were measured while standing against a meter rule with the head in Frankfurts' position after removing their shoes and their weight was measured using a weighing scale ZT WHO Scale to the nearest $0.1 \mathrm{~kg}$.

\section{Scanning technique}

The Ultrasound examination was carried out with the subjects in the supine and right anterior oblique position following an overnight fast. Subjects were exposed from the xiphisternum to the pelvic brim, ultrasound gel was applied to the right upper quadrants of the abdomen, and the transducer placed in the epigastrium in both the transverse and longitudinal planes to assess the main portal vein during quiet respiration, when the visualization of the portal vein was optimal, measurements were made at a point where the portal vein crosses anterior to the inferior vena cava (IVC) (fig. 1), with the calipers placed between the inner margins of the echogenic walls of the vessel. Measurements (in $\mathrm{mm}$ ) were made twice by each of the two sonographers and the average values of the two measurements were recorded as the final value. Demographic data such as age, sex, weight, and height were recorded and the body mass index (BMI) was calculated using Quetelets' formula: BMI = weight $(\mathrm{Kg}) /$ height $\left(\mathrm{m}^{2}\right)^{6}$.

\section{Data analysis}

Data capture sheet was used to record all the measurements obtained. Data analysis was done using Statistical Package for Social Science (SPSS) version 22.0 (SPSS Chicago, Illinois, USA). Descriptive statistics (mean, standard deviation, frequency, and percentages) and Pearson product moment correlation were used for the analysis. Statistical significance was considered at $\mathrm{P}<0.05$.

\section{Results}

A total of 201 apparently healthy adults were enrolled for the study. The study constitutes $72(35.82 \%)$ males and $129(64.18 \%)$ females. The subjects were between the ages of $18-80$ years, with mean age of $32.5 \pm 11.3$ years. Participants within the age group of 25-29 years had the highest frequency of $15(7.46 \%)$, while those within the age group of 45-49 years had the lowest frequency of 3 $(1.49 \%)$, as shown in table 1 . 
Table 1: Frequency distribution base on age and sex of subjects.

\begin{tabular}{|c|c|c|c|c|c|c|}
\hline $\begin{array}{c}\text { Age } \\
(\text { YRS) }\end{array}$ & & $(\%)$ & $\begin{array}{l}\text { Fer } \\
\mathbf{N}\end{array}$ & $(\%)$ & $\begin{array}{l}\text { Total } \\
\text { N }\end{array}$ & $(\%)$ \\
\hline$<20$ & 5 & $2.49 \%$ & 14 & $6.97 \%$ & 19 & $9.45 \%$ \\
\hline $21-24$ & 6 & $2.99 \%$ & 19 & $9.45 \%$ & 25 & $12.44 \%$ \\
\hline $25-29$ & 15 & $7.46 \%$ & 34 & $16.92 \%$ & 49 & $24.38 \%$ \\
\hline $30-34$ & 14 & $6.97 \%$ & 24 & $11.94 \%$ & 38 & $18.91 \%$ \\
\hline $35-39$ & 12 & $5.97 \%$ & 14 & $6.97 \%$ & 26 & $12.94 \%$ \\
\hline $40-44$ & 5 & $2.49 \%$ & 12 & $5.97 \%$ & 17 & $8.46 \%$ \\
\hline $45-49$ & 3 & $1.49 \%$ & 5 & $2.49 \%$ & 8 & $3.98 \%$ \\
\hline 50+ & 12 & $5.97 \%$ & 7 & $3.48 \%$ & 19 & $9.45 \%$ \\
\hline $32.5 \pm 11.3$ & 72 & $35.82 \%$ & 129 & $64.18 \%$ & 201 & $100 \%$ \\
\hline
\end{tabular}

Participants within the age group of 45-49 years had the age group 25-29 years had the least value of $9.12 \pm$ the highest value of $10.50 \pm 1.60 \mathrm{~mm}$ and those within $1.52 \mathrm{~mm}$ as shown in table 2 .

Table 2: Distribution of mean PV diameter in relation to age.

$\begin{array}{ccc} & \begin{array}{c}\text { Age } \\ \text { (Years) }\end{array} & \begin{array}{c}\text { Average PV DIAMETER (PVD) } \\ \text { (Mean } \pm \text { STD) } \mathbf{m m}\end{array} \\ <20 & \mathbf{9 . 4 2} \pm \mathbf{1 . 3 0} \\ \mathbf{2 1}-\mathbf{2 4} & \mathbf{9 . 1 2} \pm \mathbf{1 . 5 4} \\ \mathbf{2 5}-\mathbf{2 9} & \mathbf{9 . 1 2} \pm \mathbf{1 . 5 2} \\ \mathbf{3 0}-\mathbf{3 4} & \mathbf{9 . 9 5} \pm \mathbf{1 . 3 1} \\ \mathbf{3 5}-\mathbf{3 9} & \mathbf{9 . 6 9} \pm \mathbf{1 . 3 2} \\ \mathbf{4 0}-\mathbf{4 4} & \mathbf{9 . 2 4} \pm \mathbf{1 . 5 6} \\ & \mathbf{4 5}-\mathbf{4 9} & \mathbf{1 0 . 5 0} \pm \mathbf{1 . 6 0} \\ & \mathbf{5 0}+ & \mathbf{9 . 4 7} \pm \mathbf{1 . 2 6} \\ \text { Mean } \pm \text { SD } & \mathbf{3 2 . 5} \pm \mathbf{1 1 . 3} & \mathbf{9 . 6 0} \pm \mathbf{1 . 4 1}\end{array}$

The mean values of portal vein diameter in males and females were $9.71 \pm 1.42 \mathrm{~mm}$ and $9.53 \pm 1.46$ respectively, as shown in table 3

Table 3: Mean PV diameter in relation to gender.

\begin{tabular}{|c|c|c|}
\hline & $\begin{array}{l}\text { Age } \\
\text { (YRS) }\end{array}$ & $\begin{array}{l}\text { Male } \\
(M E A N \pm S T D) ~ m m\end{array}$ \\
\hline & $<20$ & $10.40 \pm 1.14$ \\
\hline & $21-24$ & $8.83 \pm 0.98$ \\
\hline & $25-29$ & $9.60 \pm 1.18$ \\
\hline & $\mathbf{3 0}-\mathbf{3 4}$ & $10.21 \pm 1.67$ \\
\hline & $35-39$ & $9.58 \pm 1.56$ \\
\hline & $40-44$ & $9.40 \pm 1.34$ \\
\hline & $45-49$ & $10.33 \pm 2.08$ \\
\hline & $50+$ & $9.50 \pm 1.38$ \\
\hline Mean \pm SD) & $32.5 \pm 11.3$ & $9.71 \pm 1.42$ \\
\hline
\end{tabular}

Female PVD
(MEAN \pm STD $) \mathbf{m m}$
9.07 $\pm \mathbf{1 . 2 1}$
$\mathbf{9 . 2 1} \pm \mathbf{1 . 6 9}$
$\mathbf{8 . 9 1} \pm \mathbf{1 . 6 2}$
$\mathbf{9 . 7 9} \pm \mathbf{1 . 0 6}$
$\mathbf{9 . 7 9} \pm \mathbf{1 . 1 2}$
$\mathbf{9 . 1 7} \pm \mathbf{1 . 7 0}$
$\mathbf{1 0 . 6 0} \pm \mathbf{1 . 5 2}$
$\mathbf{9 . 4 3} \pm \mathbf{1 . 1 3}$
$\mathbf{9 . 3 5} \pm \mathbf{1 . 4 6}$

This study found the mean weight of $66.32 \pm 10.65 \mathrm{~kg}$ and the mean height of $1.66 \pm 0.08 \mathrm{~m}$ respectively with mean portal vein diameter of $9.60 \pm 1.14 \mathrm{~mm}$. It also shows participants within the age group 45-49 years had the highest mean weight and height of $82.63 \pm 18.26 \mathrm{~kg}$ and $1.69 \pm 0.08 \mathrm{~m}$ respectively with mean portal vein diameter of $10.50 \pm 1.60 \mathrm{~mm}$ while the age group $<20$ years had the least mean weight and height of $55.21 \pm$ $11.55 \mathrm{~kg}$ and $1.63 \pm 0.08 \mathrm{~mm}$ respectively with mean portal vein diameter of $9.42 \pm 1.30 \mathrm{~mm}$. There was a positive correlation between the average portal vein diameter and weight, height for both sexes with correlation coefficients 
of 0.857 and $\mathrm{P} \leq 0.005$ and 0.794 and $\mathrm{P} \leq 0.001$ respec- tively as shown in table 4 .

Table 4: Participants weight, height and mean Portal Vein Diameter according to age group.

\begin{tabular}{|c|c|c|c|c|}
\hline & $\begin{array}{l}\text { Age } \\
\text { (YEARS) }\end{array}$ & $\begin{array}{l}\text { Weight } \\
\text { (MEAN } \pm \text { STD)kg }\end{array}$ & $\begin{array}{l}\text { Height } \\
(\text { MEAN } \pm \text { STD }) \mathrm{m}\end{array}$ & $\begin{array}{l}\text { Mean PVD } \\
\text { (MEAN } \pm \text { STD) mm }\end{array}$ \\
\hline & $<20$ & $55.21 \pm 11.55$ & $1.63 \pm 0.08$ & $9.42 \pm 1.30$ \\
\hline & $21-24$ & $\mathbf{5 8 . 4 4} \pm 13.79$ & $1.65 \pm 0.10$ & $9.12 \pm 1.54$ \\
\hline & $25-29$ & $61.49 \pm 13.74$ & $1.64 \pm 0.11$ & $9.12 \pm 1.52$ \\
\hline & $30-34$ & $69.61 \pm 15.27$ & $1.65 \pm 0.11$ & $9.95 \pm 1.31$ \\
\hline & $35-39$ & $74.19 \pm 16.79$ & $1.66 \pm 0.08$ & $9.69 \pm 1.32$ \\
\hline & $40-44$ & $64.82 \pm 10.99$ & $1.63 \pm 0.09$ & $9.24 \pm 1.56$ \\
\hline & $45-49$ & $82.63 \pm 18.26$ & $1.69 \pm 0.08$ & $10.50 \pm 1.60$ \\
\hline & $50+$ & $67.32 \pm 10.65$ & $1.66 \pm 0.10$ & $9.47 \pm 1.26$ \\
\hline al & $32.5 \pm 11.3$ & $66.32 \pm 10.65$ & $1.66 \pm 0.08$ & $9.60 \pm 1.41$ \\
\hline
\end{tabular}

The mean portal vein diameter for both male and female participants with normal Body Mass Index was 9.77 $\pm 1.41 \mathrm{~mm}$ and $8.76 \pm 1.37 \mathrm{~mm}$ respectively. There was a positive correlation between the PV diameter and BMI of the participants $(\mathrm{P} \leq 0.010)$ as shown in table 5 and figure 2 .

Table 5: Participants BMI and Average Portal Vein Diameter.

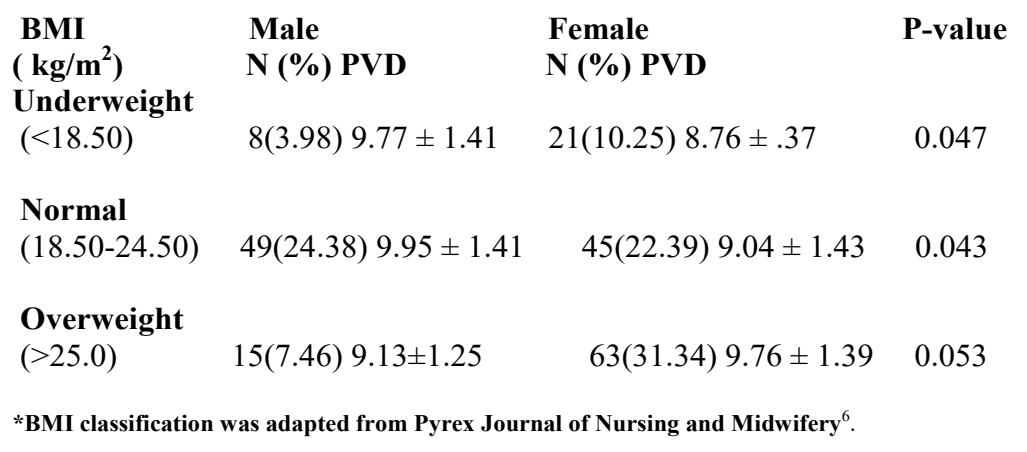

\section{Discussion}

Ultrasound imaging plays an important role in the assessment of the portal vein diameter, flow rate, and peak systolic velocity which gives an accurate and a reliable method of diagnosing disease conditions of the liver such as chronic liver diseases ${ }^{2,7}$.

The mean portal diameter in this study was $9.60 \pm 1.41 \mathrm{~mm}$. Similar findings were reported by other studies in Nigeria; Usman et $\mathrm{al}^{7}$, found $10.87 \pm 0.81 \mathrm{~mm}$ in North-Eastern Nigeria, Ukperi ${ }^{8}$ and Adeyekun et $\mathrm{al}^{5}$ in south western Nigeria found $8.1 \pm 0.12 \mathrm{~mm}$ and $10.3 \pm 1.5 \mathrm{~mm}$ respectively. Anakwue et $\mathrm{al}^{9}$ in South Eastern Nigeria found $11.5 \pm 1.5 \mathrm{~mm}$ as the mean portal vein diameter. This similarity in the reported portal vein diameter could be due to the similarities in the methods adopted by these studies as the measurements were all done using the trans-abdominal approach and using similar probe frequencies.
However, studies conducted in other countries also report similar findings. Ongoiba et al10 in Bamako, Mali reported a mean value of $9.2 \pm 2.6 \mathrm{~mm}$. Hawaz et $\mathrm{al}^{2}$ among Ethiopians reported a mean value of $10.0 \pm 1.8 \mathrm{~mm}$, Webb et $\mathrm{al}^{11}$ reported mean portal vein diameter of $6.3 \pm 2.3 \mathrm{~mm}$, Weinerb et $\mathrm{al}^{12}$ in USA reported a mean value of $11 \pm 2.0 \mathrm{~mm}$, Rokni-Yazdi et $\mathrm{al}^{13}$ in Iran, reported a mean value of $9.36 \pm 1.65 \mathrm{~mm}$, Bhattacharya et $\mathrm{al}^{1}$ in West Bengal, India reported a mean value of $10.02 \pm 0.89 \mathrm{~mm}$. The reported values of the PV diameter from studies from other countries and among different ethnic groups and races, with varying samples sizes, did not vary with the values obtained from our study. This implies that using similar methodology and equipment in the hands of a qualified sonographer and / or sonologist, the measurement of the portal vein diameter can be reproducible and reliable. 
However, one of the limitations of this present study is that only the diameter of the portal vein was measured and not the portal flow which was also assessed by Rokni-Yazdi et $\mathrm{al}^{13}$

Some literature haSdocumented portal vein diameter to vary with age, gender, and Body Mass Index. The mean portal vein diameter among males in this study was higher than females, being $9.71 \pm 1.42 \mathrm{~mm}$ and $9.35 \pm 1.46 \mathrm{~mm}$ respectively. The difference is not statistically significant $(\mathrm{p}<0.05)$. This is in agreement with the reports of Hawaz et $\mathrm{al}^{2}$, Gosh et $\mathrm{al}^{3}$, Adeyekun et $\mathrm{al}^{5}$, Siddiqui et $\mathrm{al}^{14}$, Saha et $\mathrm{al}^{15}$ and Goyal et $\mathrm{al}^{16}$ who found no significant influence of gender on portal vein diameter. This similarity may be attributed to larger number of females participants involved in the studies. Moreover, the influence of age on portal vein diameter has been documented by various researchers with varied results. This study showed positive correlation of age with portal vein diameter $(p<0.01)$. This is in line with the study of Bhattacharya et $\mathrm{al}^{1}, \mathrm{Ha}-$ waz et $\mathrm{al}^{2}$, Gosh et $\mathrm{al}^{3}$, Anakwue et $\mathrm{al}^{9}$, Weinreb et $\mathrm{al}^{12}$, Saha et $\mathrm{al}^{15}$ and Patriquin et $a 1^{17}$. It however contradicts the findings of Adeyekun et $\mathrm{al}^{5}$ who reported there was no statistically significant influence of age on portal vein diameter. This variation in the portal vein diameter may be attributed to difference in the phase of respiration at the time of ultrasonographic measurements.

This study also showed a positive correlation between Body Mass Index (BMI) and portal vein diameter $(p<0.01)$. This is in agreement with the reports of Saha et $\mathrm{al}^{15}$ andGosh et $\mathrm{al}^{3}$.However, it was in contrast to the findings of Adeyekun et $\mathrm{al}^{5}$ who reported that there was no statically significant influence of BMI on portal vein diameter. The difference in the reported value may be attributed to the sedentary life style in the Western part of Nigeria compared to the nomads in northern Nigeria who are either farming, grazing or leaving an active life. Rajashree et $\mathrm{al}^{18}$ also reported a positive correlation between the portal vein diameter and other anthropometric parameters. The knowledge of these normal variations is essential for surgeons, sonologist and sonographers during diagnosis of problems that may relate to the portal system.

\section{Conclusion}

This study has established baseline values for normal range of portal vein diameter in apparently healthy adults in a Northern Nigerian population to be $9.60 \pm 1.41 \mathrm{~mm}$ and also found that PV diameter positively correlates with anthropometric variables.

\section{Acknowledgement}

We acknowledge the Head of Department of Radiology Dr Yusuf Aliyu, and other staff of the department of Radiology ATBU, Bauchi for their support during data collection.

\section{Authors' contribution}

GL: Participated in conceptualization and design of the work, data acquisition, analysis, manuscript drafting, revision for its intellectual content and approval of the final work.

MS: Participated in conceptualization and design of the work, data acquisition, analysis, manuscript drafting, revision for its intellectual content and approval of the final work.

DZJ: Participated in data acquisition, manuscript drafting, revision for its intellectual content and approval of the final work.

NCI: Participated in conceptualization and design of the work, revision for its intellectual content and approval of the final work.

SHG: Participated in conceptualization and design of the work, revision for its intellectual content and approval of the final work.

\section{References}

1. Bhattacharya J, Aditi D, Anish B. Sonographical Assessment of Portal vein diameter in northern part of West Bengal, India oct. Jour. Env. Res. 2013;1(3)231-34. PubMed 2. Hawaz Y, Admassie D, Kebede T. Ultrasound Assessment of Normal Portal Vein Diameter in Ethiopians Done at Tikur Anbessa Specialized Hospital. East Cent Afr J Surg. 2012; 17 (1):90-93. PubMed

3. Ghosh TN, Bernerjee M, Basu S, Das R, et al. Assessment of normal portal vein diameter in children. Journal of Tropical Gastroentrology 2014; 35(2): 79-84

4. Mandal L, Mandal S.K, Bandyopadhyay D, Datta S. Correlation of portal vein diameter and splenic size with gastro-oesophageal varices in cirrhosis of liver. Journal, Indian Academy of Clinical Medicine. 2011; 12(4): 266-70

5. Adeyekun, A.A., Tsebi, H.B., Grey Scale SonographicAssessment of Portal Vein Diameter in Healthy Nigerian Adults. Journal of Medicine and Biomedical Research. 2014; 13(1): $17-24$

African Health Sciences Vol 16 Issue 4, December, 2016 
6.Huxley R., Mendis S., Zheleznyakov E., Reddy S., Chan J. Body mass index, waist circumference and waist: hip ratio as predictors of cardiovascular risk - a review of the literature European Journal of Clinical Nutrition. 2010; 64.16-22

7. Usman AU, Ibinaiye P, Ahidjo A, Tahir A, Sa'ad ST, et al. Ultrasound Determination of Portal Vein Diameter in Adult Patients with Chronic Liver Disease in North-Eastern Nigeria. Sub-Saharan Afr J Med. 2015; 2(2):57-63.

8. Ukperi OS.Ultrasonographic measurement of normal portal vein diameter in Nigerian adults. Dissertation submitted to the faculty of radiology, West African college of surgeons. 2010.

9. Anakwue AC, Anakwue RC, Ugwu AC, et al. Sonographic evaluation of normal portal Vein diameter in Nigerians. European Journal of scientific research. 2009; 36 (1): 114-17

10. Ongoiba N, Sissoko F, Ouologuen I, Berete S, Traore AK. Portal vein sonographic anatomy. Morphologie. 2003; 87:29-32 PubMed .

11. Webb LJ, Berger A, Sherlock S. Grey Scale ultrasonography of the portal vein. Lancet. 1977; 2:675-67.
12. Weinreb J, Kumari S, Phillips G, Pochaczevsky R. Portal vein measurement by realtime sonography. Am J Roentgenology. 1982; 139:497- 99.

13. Rokni-Yazdi H, Sotoudeh H. Assessment of Normal Doppler Parameters of Portal Vein and Hepatic Artery in 37 Healthy Iranian Volunteers. Iran J Radiol. 2006; 3(4):213-16

14. Siddiqui TR, Hassan N, Gul P. Effect of anthropometric measurements on portal vein and hepatosplenic span. Pak J Med Sci. 2013; 29(4): 1077-80. PubMed 15. Saha N, Sarkar R, Singh MM. Portal vein diameter in a tertiary care centre in North-East India. Journal of Dental and Medical Sciences. 2015; 14(12):110-13

16. Goyal AK, Pokharna DS,S Sharma SK. Ultrasonic measurement of portal vasculature in the diagnosis of portal hypertension. A controversial subject reviewed. $J$ Ultrasound Med. 1990 9:45-48

17. Partriquin HB, Peareault G, Gignon L, Boisvert J, Filiatrant D, et al. Normal portal venous diameter in children. Paed Radiol 1990; 20:451-53

18. Rajashree Sheelawant Raut, and B. H. Bahetee. Study of Anatomical Dimensions of Portal Vein. Sch. J. App. Med. Sci., 2015; 3(3E):1343-45 